\title{
Preliminary study of biochemical role of serum fetuin-a level and its gene polymorphism in diabetic patients with microalbuminuria
}

\begin{abstract}
Background: Microalbuminuria (MA) is a risk factor for cardiovascular disease. Fetuin-A is a hepatokines involved in insulin resistance (IR) and type 2diabetes. The aim of this study was to evaluate the possible association between both serum level and (Thr256Ser) gene polymorphism of fetuin- A and the pathogenesis of MA in type 2 diabetic patients, and determine its correlation with some vascular and oxidative stress markers.

Methods: 50 patients with type 2 diabetes divided into two equal groups (normoalbuminuria and microalbuminuria groups) and 25 healthy subjects as controls. ELISA was used to measure serum fetuin-A and insulin levels, then assessment of IR. Fetuin- A gene (Thr256Ser) polymorphism was done using PCR-RFLP technique. Serum nitric oxide (NO) and ischemia modified albumin (IMA) were measured, in addition to routine investigations.
\end{abstract}

Results: Significant increase of serum IMA, NO, insulin and fetuin-A levels were documented in the microalbuminuric patient group as compared to the other two groups, with no statistically significant difference as regard the three fetuin-A genotypes either between both diabetic patient groups or between them and the control. By using multiple logistic regression analysis, Fetuin-A, is the most important predictor of MA.

Conclusion: So, it could be concluded that the higher levels of fetuin-A may be an independent novel risk factor for MA in type 2 diabetic patients, in spite of the non significant difference either between normoalbuminuric and microalbuminuric diabetic or between them and control according to the frequencies of the three fetuin-A genotype.

Keywords: diabetes mellitus, microalbuminuria, fetuin-a, no, IMA
Volume 2 Issue 5 - 2015

\section{Manal M El-Batch, Hala E Hamouda, Sobhy A Hassan, Wael Farag Mohamed, Hemat E El-Horany \\ Medical Biochemistry Department, Tanta University, Egypt}

Correspondence: Hala E Hamouda, Medical Biochemistry Department, Tanta University, Egypt Tanta Elstaad, Kamal Ghoraba street, Egypt, Email hala_el-said@hotmail.com

Received: May 17,20I5 | Published: December 08, 2015
Abbreviations: MA, microalbuminuria; NO, nitric oxide; IMA, ischemia-modified albumin; IR, insulin resistance; UACR, urinary albumin/creatinine ratio; $\mathrm{TG}$, triglycerides; $\mathrm{TG}$, total cholesterol; HDL, high-density lipoprotein; LDL, low-density lipoprotein; HOMA-IR, homeostasis model assessment of IR

\section{Introduction}

Microalbuminuria (MA) is the result of increased vascular permeability which develops as a renal manifestation of generalized vascular endothelial injury, that may make it a valuable early predictor of atherosclerosis and cardiovascular mortality, so the early identification and treatment of patients at increased risk for MA may be important to limit the excess renal and cardiovascular disease associated with type 2 diabetes. $^{1}$ Therefore, more sensitive and specific biomarkers are required to predict the development of MA early enough to improve clinical management and to allow for timely intervention to prevent complications. ${ }^{2}$

Increased oxidative stress and reduced nitric oxide (NO) bioavailability play a causal role in endothelial cell dysfunction occurring in the vasculature of diabetic patients. ${ }^{3}$ In the kidney, NO controls both afferent and efferent vascular tone, the ultra filtration coefficient and medullary blood flow. ${ }^{4}$
Ischemia-Modified Albumin (IMA) is the variant form of human serum albumin of which $\mathrm{N}$-terminal end has been altered after it was exposed to oxidative stress and/or ischemia, so it is considered as a novel marker for both tissue ischemia and oxidative stress. ${ }^{5}$

Fetuin-A is one of the most important hepatokines and is well known to be not only a powerful calcification inhibitor, but also, an endogeneous inhibitor of the insulin receptor tyrosine kinase in liver and skeletal muscle, resulting in insulin resistance (IR) in these target tissues. ${ }^{6,7}$ The human fetuin-A gene is located on chromosome 3q27, this segment of DNA contains genetic susceptibility loci for type 2 DM and metabolic syndrome. ${ }^{8}$

So, the aim of the study was to investigate the role of serum fetuin-A and its gene polymorphism in the pathogenesis of MA in type 2 diabetic patients by determining its relation with some vascular and oxidative stress markers.

\section{Materials and methods}

The study population consisted of 50 patients, including 25 normoalbuminuric patients with type 2 diabetes (group II) and 25 microalbuminuric patients with type 2 diabetes (group III). Also, 25 matched healthy volunteers with no known chronic/systemic disorder 
and not on any medications were included to serve as healthy controls (group I). The control and patients were matched for age and gender.

The urinary albumin/creatinine ratio (UACR) in the morning spot urine collections was used to diagnose normoalbuminuria as $<30 \mathrm{mg} / \mathrm{g}$ and microalbuminuria as $30-300 \mathrm{mg} / \mathrm{g}$. The diabetic patients were recruited from the Outpatient Clinics of Endocrinology and Diabetes at Tanta University Hospital.

Subjects excluded from this study were those with other causes of MA including: acute febrile illness, liver dysfunction, congestive heart failure, malignancy, heart valve disorders, history of cerebrovascular or cardiovascular disorders, abnormal thyroid functions and other renal disorders. All subjects gave their written informed consent before participation. The study protocol was approved by the Local Ethics Committee of the Faculty of Medicine, Tanta University, and was in accordance with the principles of the Declaration of Helsinki II.

\section{All the studied groups were subjected to the following}

a. Clinical Evaluation: Includes history taking and full clinical examination.

b. Estimation of urinary albumin to creatinine ratio in a morning random urine spot collection. ${ }^{9}$ Morning urine samples were analyzed for albumin concentration by turbidimetry ${ }^{10}$ and creatinine by Jaffe's reaction, ${ }^{11}$ then UACR was expressed as $\mathrm{mg} / \mathrm{g}$.

c. Laboratory investigations: Five milliliters venous blood was taken after an overnight fasting. Obtained serum samples were stored at $-80^{\circ} \mathrm{C}$ until subsequent analysis. Genomic DNA was extracted from $200 \mu \mathrm{L}$ samples of EDTA-anticoagulated peripheral blood using the G-spin ${ }^{\mathrm{TM}}$. Total DNA Extraction Mini Kit supplied by iNtRON biotechnology (Korea) for genotyping for the common functional polymorphisms on fetuin- A (Thr256Ser) using polymerase chain reactionrestriction fragment length polymorphism technique (PCRRFLP). Then, the following laboratory investigations were carried out

\section{Routine laboratory investigations}

They included estimation of serum fasting and postprandial glucose, urea, creatinine, triglycerides (TG), total cholesterol (TC) and high-density lipoprotein (HDL) cholesterol using enzymatic colorimetric methods. Low-density lipoprotein (LDL) cholesterol was calculated by Friedewald's formula. ${ }^{12}$

Estimated glomerular filtration rate (eGFR) using the Modification of Diet in Renal Disease (MDRD) study equation

eGFR, in $\mathrm{ml} / \mathrm{min}$ per $1.73 \mathrm{~m}^{2}=175 \times($ serum creatinine, in $\mathrm{mg} /$ $\mathrm{dl})^{-1.154} \times(\text { Age })^{-0.203} \times(0.742$ if female $) \times(1.21$ if black $){ }^{13}$

\section{Specific laboratory investigations including}

a. Estimation of serum (NO) level as a nitrite, based on the Griess reaction. ${ }^{14}$

b. Estimation of serum Ischemia modified albumin (IMA) by colorimetric cobalt-albumin binding assay. IMA was expressed as absorbance units (ABSU). ${ }^{15}$ c. Estimation of serum insulin level by enzyme-linked immuno sorbent assay (ELISA) kit (Diagnostic Automation, INC., USA) and assessment of IR by calculation of homeostasis model assessment of IR (HOMA-IR), according to the following formula: Fasting insulin $(\mu \mathrm{IU} / \mathrm{mL}) \mathrm{x}$ Fasting glucose $(\mathrm{mg} / \mathrm{dL}) / 405 .{ }^{16}$

d. Estimation of serum fetuin-A level by an ELISA kit (Omni Kine, USA).

e. Genotyping for the fetuin- A gene (Thr256Ser) polymorphism $(c .766 \mathrm{C} \rightarrow \mathrm{G})$; $(\mathrm{Thr} 256 \mathrm{Ser})$ performed by (PCR- RFLP) technique according to previously published protocols as following: ${ }^{17,18}$ The extracted DNA was subjected to PCR amplification for Fetuin-A gene using PCR Master Mix; Maximo Taq DNA Polymerase 2X-preMix supplied from (Gene ON, Germany). The DNA fragments containing fetuin-A $(\mathrm{C} \rightarrow \mathrm{G})$; (Thr256Ser) polymorphism were amplified using oligonucleotide primers (F5'-GTCACCCCTCCTTGTAAC-3' and R5'-CCCCAATGAGACCACA-3') supplied from (Biolegio, Holland). The PCR conditions were as follows: initial denaturation at $95^{\circ} \mathrm{C}$ for 5 minutes, 35 cycles of denaturation at $94^{\circ} \mathrm{C}$ for one minute, annealing at $56^{\circ} \mathrm{C}$ for one minute, and extension at $72^{\circ} \mathrm{C}$ for one minute; and a final extension at $72^{\circ} \mathrm{C}$ for 15 minutes. The PCR product (405bp) was digested with the Fast Digest $\AA$ SacI restriction enzyme supplied from (Thermo Scientific). The digested products were separated by electrophoresis on a $2 \%(\mathrm{w} / \mathrm{v})$ agarose gel stained with ethidium bromide. Allele $\mathrm{C}$ does not contain the SacI site and remains undigested as $405 \mathrm{bp}$ fragments whereas allele $\mathrm{G}$ yields 193- and 212-bp fragments (Figure 1).

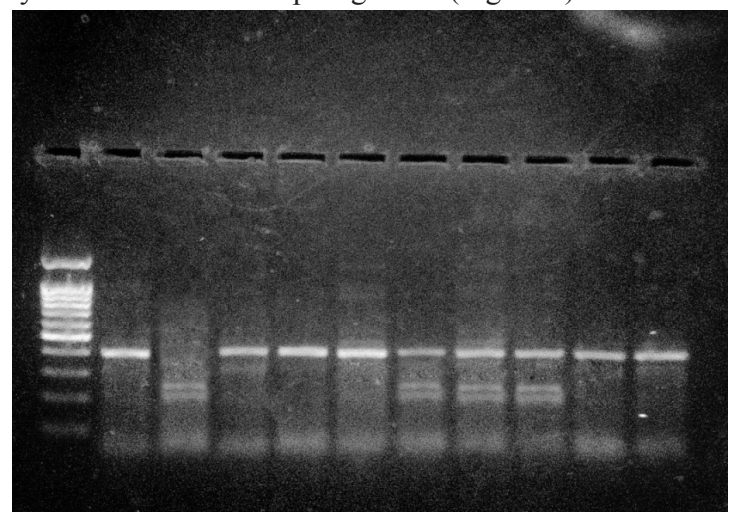

Figure I Ethidium bromide stained agarose gel electrophoresis of RFLP-PCR for fetuin-A gene polymorphism (C G);Thr256Ser following sac I restriction digestion for some samples.

Above figure showed polymerase chain reaction (PCR) and restriction fragment length polymorphism analysis of fetuin-A gene $(C \rightarrow G)$; Thr256Ser polymorphism separated on an agarose gel.

A) Lane (I): Represented DNA size marker $100-1500$ bp served as a reference for DNA fragment size.

B) Lanes $(2,4,5,6,10$, I I): Showed one band at 405 bp and they are Thr/Thr (CC); homozygote type for the absence of the sacl restriction site.

C) Lanes (7-9): Showed 3 bands at 405, 193- and 212-bp and they are Thr/ Ser (CG); heterozygote type for the presence and absence of the sacl restriction site.

D) Lane (2): Showed 2 bands at 193- and 2I2-bpand they are Ser/Ser (GG); homozygote for the resence of the sacl restriction site. 


\section{f. There are three possible genotypes for the fetuin-A:}

i. Thr/Thr (CC): homozygote for the absence of the sacI restriction site resulting in one band at $405 \mathrm{bp}$.

ii. $\mathrm{Thr} / \mathrm{Ser}(\mathrm{CG})$ : heterozygote for the presence and absence of the sacI restriction site resulting in three bands at $405 \mathrm{bp}$, 212 bp and 193- bp.

iii. Ser/Ser(GG): homozygote for the presence of the sacI restriction site resulting in two bands at $212 \mathrm{bp}$ and $193 \mathrm{bp}$.

\section{Statistical analysis}

Data were analyzed using SPSS software (version 11, SPSS Inc., Chicago, Illinois). Most data are expressed as mean \pm standard deviation $( \pm \mathrm{SD})$ for quantitative variables, whereas the frequencies of various alleles and genotypes were compared by Chi-square test $(\chi 2)$. For each analysis, an odds ratio (OR) and $95 \%$ confidence interval (CI) were calculated. Comparison between groups was conducted using one-way analysis of variance (ANOVA) followed by Tukey's post hoc test. Pearson's correlation analysis was used to examine the relationships between the studied parameters. A p-value $<0.05$ was considered significant. To determine the associations of potential determinants with the development of MA, multiple logistic regression analysis was done, where the presence of MA was the dependent variable and potential determinants for development of MA were independent variables.

\section{Results}

Demographic and clinical characteristics of all studied groups are presented in (Table 1) in which increased disease duration was documented in microalbuminuric patients (group III) than normoalbuminuric patients (group II). Significant increase of blood pressure was detected in both diabetic groups as compared to control group. Laboratory characteristics of the studied groups are shown in Table 2. Significant increase of serum urea, creatinine, glucose, TC, TG and LDL-C levels were found in microalbuminuric patients as compared to both normoalbuminuric patients and controls, with significant decrease of serum HDL-C levels as compared to both groups. Normoalbuminuric patients showed significant higher levels of serum glucose, TC and LDL-C, as compared to controls with no significant difference between them as regard serum urea, creatinine, TG and HDL-C levels. Also, there were significant increase of serum insulin, IMA, NO and fetuin-A levels in addition to HOMA/IR in both diabetic groups as compared to controls, with significantly higher values in microalbuminuric patients as compared to normoalbuminuric patients. However, there was no significant difference as regard $\mathrm{NO}$ levels between the controls and normoalbuminuric patients.

Table I Demographic and clinical data of all of the studied groups

\begin{tabular}{|c|c|c|c|c|c|c|}
\hline \multicolumn{2}{|c|}{ Variables } & $\begin{array}{l}\text { Group I } \\
(n=25)\end{array}$ & $\begin{array}{l}\text { Group II } \\
(n=25)\end{array}$ & $\begin{array}{l}\text { Group III } \\
(n=25)\end{array}$ & $F / t / X^{2}$ & P-value \\
\hline \multicolumn{2}{|c|}{ Age (years) } & $49.5 \pm 7.2$ & $55.2 \pm 11.2$ & $54.1 \pm 7.5$ & $F=2.95$ & $0.06 \mathrm{~ns}$ \\
\hline \multirow{2}{*}{ Sex } & Female (\%) & $21(84 \%)$ & $19(76 \%)$ & $22(88 \%)$ & \multirow{2}{*}{$X^{2}=1.29$} & \multirow{2}{*}{$0.53(\mathrm{~ns})$} \\
\hline & Male (\%) & $4(16 \%)$ & $6(24 \%)$ & $3(12 \%)$ & & \\
\hline \multicolumn{2}{|c|}{ Duration (years) } & - & $5.5 \pm 3.4$ & $8.1 \pm 4.6$ & $\mathrm{t}=-2.22$ & 0.031 \\
\hline \multicolumn{2}{|c|}{$\mathrm{SBP}(\mathrm{mmHg})$} & II $4.4 \pm 7.4$ & $123.6 \pm 7.8 *$ & $121.2 \pm 7.8^{*}$ & $F=9.6$ & $<0.001$ \\
\hline \multicolumn{2}{|c|}{$\mathrm{DBP}(\mathrm{mmHg})$} & $77.2 \pm 4.1$ & $82 \pm 6.9 *$ & $79.6 \pm 7.9$ & $F=3.4$ & 0.039 \\
\hline
\end{tabular}

Healthy Controls (Group I), Normoalbuminuric Type 2 DM (Group II), Microalbuminuric Type 2 DM (Group III), systolic blood pressure (SBP), diastolic blood pressure (DBP). Ns, non-significant $(P>0.05) \mathrm{F}$, anova test; $\mathrm{X}^{2}$, chi square test, $t$, t-test. *significant as compared to Group I

Table 2 Biochemical findings among all the studied groups

\begin{tabular}{|c|c|c|c|c|c|}
\hline Variables & (Group I) $(n=25)$ & (Group II) $(n=25)$ & (Group III) $(n=25)$ & $\mathbf{F}$ & P-value \\
\hline UACR (mg/g) & $16.7 \pm 9.3$ & $18.6 \pm 5.9$ & $73.5 \pm 52 * \dagger$ & 27.5 & $<0.001$ \\
\hline Urea (mg\%) & $25.1 \pm 7.0$ & $32.2 \pm 8.9$ & $71.1 \pm 17 * \dagger$ & 109.9 & $<0.001$ \\
\hline Creat. (mg\%) & $0.7 \pm 0.1$ & $0.8 \pm 0.2$ & $0.9 \pm 0.3^{*}+$ & 5.4 & 0.001 \\
\hline eGFR $\left(\mathrm{ml} / \mathrm{min}\right.$ per $\left.1.73 \mathrm{~m}^{2}\right)$ & $92.2 \pm 16.7$ & $94.3 \pm 28.8$ & $70.4 \pm 24.9 * \dagger$ & 7.6 & 0.001 \\
\hline Fasting glucose (mg\%) & $79.0 \pm 8.0$ & $212.3 \pm 53.9 *$ & $244.5 \pm 63.6 * \dagger$ & 82.3 & $<0.001$ \\
\hline 2-h PP blood glucose (mg\%) & $93.8 \pm 16.6$ & $278.1 \pm 59.9 *$ & $356.3 \pm 52.4^{*}+$ & 206.1 & $<0.001$ \\
\hline $\mathrm{TC}(\mathrm{mg} \%)$ & $|72.6 \pm 3| .5$ & $228.2 \pm 59.1 *$ & $268.2 \pm 49.2 * \dagger$ & 25.03 & $<0.001$ \\
\hline TG (mg\%) & $95.9 \pm 14.2$ & I $4.4 \pm 40.5$ & $136.7 \pm 34.7 * \dagger$ & 10.3 & $<0.001$ \\
\hline HDL-C (mg\%) & $49.7 \pm 4.4$ & $46.9 \pm 9.5$ & $38.8 \pm 5.8^{*} \dagger$ & 16.9 & $<0.001$ \\
\hline LDL-C (mg\%) & $104.3 \pm 29.5$ & $|58.4 \pm 6| .5^{*}$ & $202.1 \pm 48.2^{*} \dagger$ & 25.8 & $<0.001$ \\
\hline Fasting insulin $(\mu \mathrm{lU} / \mathrm{ml})$ & $4.2 \pm 1.3$ & $8.5 \pm 5.3^{*}$ & $13.2 \pm 4.7^{*} \dagger$ & 29.4 & $<0.001$ \\
\hline HOMA/IR & $1.1 \pm 0.3$ & $4.6 \pm 3.6^{*}$ & $7.8 \pm 4.3 * \dagger$ & 26.9 & $<0.001$ \\
\hline IMA (ABSU) & $0.2 \pm 0.1$ & $0.3 \pm 0.2^{*}$ & $0.4 \pm 0.1 *+$ & 11.9 & $<0.001$ \\
\hline
\end{tabular}


Table Continued.

\begin{tabular}{llllll} 
Variables & (Group I) $(\mathbf{n}=\mathbf{2 5})$ & (Group II) $(\mathbf{n = 2 5 )}$ & (Group III) $(\mathbf{n = 2 5})$ & $\mathbf{F}$ & $\mathbf{P}-\mathrm{value}$ \\
$\mathrm{NO}(\mu \mathrm{mol} / \mathrm{L})$ & $8.7 \pm 3.7$ & $14.3 \pm 8.9$ & $32.7 \pm 19.4^{*} \dagger$ & 25.2 & $<0.00 \mathrm{I}$ \\
Fetuin-A $(\mathrm{mg} \%)$ & $26.2 \pm 2.8$ & $31.6 \pm 1 I^{*}$ & $39.6 \pm 7.7^{*}++$ & 17.9 & $<0.00 \mathrm{I}$ \\
\hline
\end{tabular}

Healthy controls (Group I), Normoalbuminuric type 2 DM (Group II), Microalbuminuric type 2 DM (Group III), urinary albumin to creatinine ratio (UACR), estimated glomerular filtration rate (egfr) , 2 hour post prandial (2-H PP) blood glucose, total cholesterol (TC), triacylglycerol (TG),high density lipoprotein cholesterol (HDL-C), low density lipoprotein cholesterol (LDL-C), homeostasis model assessment of insulin resistance (HOMA-IR), ischemia modified albumin (IMA), nitric oxide (NO). Ns, non-significant ( $\mathrm{P}>0.05$ ) *significant as compared to Group I; $†$ significant as compared to Group II

In (Table 3, significant correlation was found between UACR and all the studied parameters except age, fasting blood glucose and TC, in both diabetic patient groups $(n=50)$, with the highest correlation found with HOMA/IR, serum insulin and fetuin-A levels. In multiple logistic regression analysis considering microalbuminuria is the outcome variable. It was found that fetuin-A followed by NO, TG and fasting insulin levels were the most important predictors of MA (Table 4). By using Receiver Operating Characteristics (ROC) curve for fetuin-A (at cutoff value $>26.5 \mathrm{mg} \%$ ), HOMA/IR (at cutoff value $>5.86$ ), $\mathrm{NO}$ (at cutoff value $>16.9 \mu \mathrm{mol} / \mathrm{L}$ ), IMA (at cutoff value $>0.24$ $\mathrm{ABSU}$ ) in group II versus group III, it was found that fetuin-A had the highest sensitivity, negative predictive value and accuracy $(96,94.4$, and 0.8 respectively) for detecting MA (data not shown) .

As regards the results of genotyping of fetuin-A gene polymorphisms, no significant differences between either the two diabetic groups [with chi-square $\left(\mathrm{X}^{2}\right)=0.09$, odds ratio=1.2, 95\% confidence interval; $0.4-3.9, \mathrm{p}$ value $=0.8$ ] (data not shown) or between both of them and control group (with $\mathrm{X}^{2}=1.13$, $\mathrm{p}$ value $=0.9$ ) according to frequencies of the different genotypes and alleles (Table 5). These data could indicate the weak relationship between the risky genotypes CG and GG and either development of diabetes or MA. It was observed that patients with the risky genotypes $\mathrm{CG}$ and $\mathrm{GG}$ had higher levels of TC, IMA and fasting insulin levels, but lower levels of HDL-C, when compared with CC genotype (data not shown).
Table 3 Person's correlation between UACR and other studied parameters in diabetic patient groups (group I, group II). $(n=50)$

\begin{tabular}{lll}
\hline \multirow{2}{*}{ Parameters } & \multicolumn{2}{l}{ UACR (mg/g) } \\
\cline { 2 - 3 } & R & P-value \\
\hline Age (years) & 0.05 & 0.8 \\
Duration (years) & 0.36 & $0.0 I^{*}$ \\
Urea (mg\%) & 0.56 & $<0.00 I^{*}$ \\
Creatinine (mg\%) & 0.52 & $<0.00 I^{*}$ \\
eGFR (ml/min per I.73m²) & -0.56 & $<0.00 I^{*}$ \\
Fasting blood glucose $(\mathrm{mg} \%)$ & 0.14 & 0.3 \\
2h-PP blood glucose $(\mathrm{mg} \%)$ & 0.34 & $0.02^{*}$ \\
TC (mg\%) & 0.17 & 0.2 \\
TAG (mg\%) & 0.72 & $<0.00 I^{*}$ \\
HDL-C (mg\%) & -0.37 & $0.007^{*}$ \\
LDL-C (mg\%) & 0.32 & $0.025^{*}$ \\
Fasting insulin ( $\mu$ lU/ml) & 0.7 & $<0.00 I^{*}$ \\
HOMA/IR & 0.77 & $<0.00 I^{*}$ \\
NO ( $\mu \mathrm{mol} / \mathrm{L})$ & 0.53 & $<0.00 I^{*}$ \\
IMA (ABSU) & 0.37 & $0.007^{*}$ \\
Fetuin-A (mg\%) & 0.54 & $<0.00 I^{*}$ \\
\hline
\end{tabular}

Table 4 Multiple logistic regression analysis using 6 biologically important variables as independent variables, and MA as the dependent variable

\begin{tabular}{|c|c|c|c|c|c|c|c|}
\hline \multirow{2}{*}{ Variables } & \multirow{2}{*}{ B } & \multirow{2}{*}{ S.E. } & \multirow{2}{*}{ Wald } & \multirow{2}{*}{ P-value } & \multirow{2}{*}{ OR } & \multicolumn{2}{|c|}{ 95.0\% C.I. for odd } \\
\hline & & & & & & Lower & Upper \\
\hline TG & -0.091 & 0.036 & 6.37 & $0.012^{*}$ & 0.913 & 0.851 & 0.98 \\
\hline NO & 0.253 & 0.091 & 7.737 & $0.005^{*}$ & 1.288 & 1.078 & 1.539 \\
\hline IMA & 1.666 & 2.901 & 0.33 & 0.566 & 5.289 & 0.018 & 1559.516 \\
\hline Fasting insulin & 0.987 & 0.435 & 5.141 & $0.023^{*}$ & 2.683 & $\mathrm{I} .143$ & 6.295 \\
\hline HOMA/IR & -0.677 & 0.447 & 2.291 & 0.13 & 0.508 & 0.212 & 1.221 \\
\hline Fetuin-A & 0.155 & 0.103 & 8.25 & $0.001 *$ & 5.454 & 3.954 & 15.429 \\
\hline Constant & -6.55 & 3.896 & 2.827 & 0.093 & 0.001 & & \\
\hline
\end{tabular}

B, regression coefficient, S.E, standard error, OR, odds ratio $\mathrm{Cl}$, confidence interval

Table 5 Comparison among the studied groups according to the frequency of fetuin -A genotype polymorphism (C $\rightarrow G) ;$ Thr256Ser, using Chi-square test

\begin{tabular}{|c|c|c|c|c|c|c|}
\hline & Group I $(n=25)$ & Group II $(n=25)$ & Group III $(n=25)$ & Total $(n=75)$ & \multicolumn{2}{|c|}{ Chi-square } \\
\hline & $\mathbf{N}(\%)$ & $\mathbf{N}(\%)$ & $\mathbf{N}(\%)$ & $\mathbf{N}(\%)$ & $\mathbf{X}^{2}$ & P-value \\
\hline $\mathrm{CC}$ & $17(68)$ & $17(68)$ & $16(64)$ & $50(66)$ & \multirow{3}{*}{1.13} & \multirow{3}{*}{$0.9(\mathrm{~ns})$} \\
\hline CG & $8(32)$ & $7(28)$ & $8(32)$ & $23(30)$ & & \\
\hline GG & $0(0)$ & $\mathrm{I}(4)$ & $\mathrm{I}(4)$ & $2(2.67)$ & & \\
\hline C allele & $42(84)$ & $4 I(82)$ & $40(80)$ & $123(82)$ & \multirow{2}{*}{0.27} & \multirow{2}{*}{$0.9(\mathrm{~ns})$} \\
\hline G allele & $8(16)$ & $9(18)$ & $10(20)$ & $27(18)$ & & \\
\hline
\end{tabular}

Ns, non significant $(\mathrm{P}>0.05)$

Citation: El-Batch MM, Hamouda HE, Hassan SA, et al. Preliminary study of biochemical role of serum fetuin-a level and its gene polymorphism in diabetic patients with microalbuminuria. J Diabetes Metab Disord Control. 20I 5;2(5):I58-I64. DOI: I0.I5406/jdmdc.20 I5.02.00053 


\section{Discussion}

The present study documented that fetuin-A level was an independent predictor for microalbuminuria, supported by the multiple logistic regression analysis. Serum fetuin-A levels showed significant increase in both patient groups as compared to controls with significant higher levels in microalbuminuric patients as compared to normoalbuminuric.

These results came in agreement with Huddam et al. ${ }^{19}$ who found higher serum fetuin-A levels in metabolic syndrome patients with MA. Also, Inoue et al. ${ }^{20}$ has documented that the higher urinary excretion of fetuin-A is a risk factor for both MA and reduction of GFR in DN in addition it may reflect an increased in its serum levels. In contrast, Ramadan et al., ${ }^{21}$ demonstrated an association between lower fetuin-A levels and microvascular complications in type 2 diabetic patients with early DN. Also, Jung et al., ${ }^{22}$ revealed that serum fetuin-A level was not significantly different according to the absence or the presence of diabetic micro angiopathies.

Fetuin-A has been known as a natural inhibitor of tyrosine kinase activity of insulin receptor. Previous epidemiological studies showed an independent association between fetuin-A and insulin resistance and future development of diabetes mellitus in general population. ${ }^{23-25}$

In the present study, fasting serum insulin levels and HOMA/IR index, the indicators of insulin resistance in type 2 diabetes, were significantly increased in both patient groups with significantly higher values in microalbuminuric patients. These findings are in agreement with the results of Esteghamati et al. ${ }^{26}$ \& Hsu et al. ${ }^{27}$ Also, our data showed significant positive correlation between serum fetuin-A and both fasting serum insulin and HOMA-IR supporting the hypothesis that fetuin-A is involved in the pathophysiology of insulin resistance.

Therefore, it is possible that the role of fetuin-A in mediating insulin resistance may underlie the association between fetuin-A and microalbuminuria. Compensatory hyperinsulinaemia, characterizing IR, could lead to endothelial dysfunction by increasing the availability of endothelin-1, decreased NO availability and by changes in intracellular calcium and magnesium metabolism. Also, hyperinsulinaemia may increase sodium lithium counter-transport activity and stimulate renal sodium reabsorption leading to volume expansion, increased adrenergic activity and hypertension. ${ }^{26}$

Furthermore, impaired insulin sensitivity is associated with mesangial hyperplasia, and renal hypertrophy and increased endothelial cell proliferation and lipid and hyaluronate deposition in the renal matrix and inner medulla, effects that may directly contribute to progressive kidney damage. ${ }^{28}$

In addition, Ix \& Sharma ${ }^{29}$ demonstrated that higher fetuin-A levels lead to suppression of adiponectin transcription in adipocytes and lower adiponectin levels reduce 5'-AMP activated protein kinase in podocytes to promote podocyte foot process effacement and albuminuria.

Other potential mechanism could explain the association between high fetuin-A levels and microalbuminuria which is the lipid profile abnormalities observed in our microalbuminuric patient that can mediate endothelial dysfunction and future cardiovascular diseases, ${ }^{30}$ supported by significant positive correlation found between serum fetuin-A level and both TAG, LDL-C levels in the current study.

It that been revealed that fetuin-A directly or indirectly leads to these changes through its inhibitory effects on the insulin receptor tyrosine kinase. Inhibition of the insulin receptor by fetuin-A may lead to increased lipolysis and efflux of free fatty acids from adipose tissue. This may, in turn, lead to increased production of apolipoprotein B-containing very-low-density lipoprotein (VLDL). Furthermore, hypertriglyceridemia may lead to a decrease in the cholesterol content of HDL enhancing HDL clearance from the circulation, thereby potentially leading to the atherogenic lipid profile as such observed in this study. ${ }^{31}$ The infiltration of atherogenic lipoproteins into the glomerular endothelium and mesangial cells can initiate a cascade of events, including adhesion molecule expression, monocyte chemo attractant production, and release of reactive oxygen species, that lead to early glomerular injury. ${ }^{32}$

Therefore, the possible explanation for our findings is the role of fetuin-A in mediating insulin resistance, lipid profile abnormalities and endothelial dysfunction which underlie the association between fetuin-A and abnormal albuminuria.

Since it has been demonstrated that at least four non synonymous polymorphisms exist in the fetuin- A gene (at amino acid positions Thr248Met $[\mathrm{C} \rightarrow \mathrm{T}]$, Thr256Ser $[\mathrm{C} \rightarrow \mathrm{G}]$, Asp276Asn $[\mathrm{G} \rightarrow \mathrm{A}]$, and Arg317Cys $[\mathrm{C} \rightarrow \mathrm{T}]$ ), genetic polymorphisms may have an effect on circulating levels of this protein. ${ }^{33}$

The most known allelic variant in clinical studies is the (Thr256Ser) which has been associated with serum fetuin-A levels, ${ }^{34}$ type 2 diabetes $^{35}$ and ischemic stroke. ${ }^{8}$

Therefore, this study aimed to examine the relationship between this common allelic variant (Thr256Ser) for fetuin-A gene and the risk of developing microalbuminuria in type 2 diabetic patients to aid in its early diagnosis. However, our data do not provide evidence for a significant association between the studied Thr256Ser polymorphism of the fetuin-A gene and neither serum fetuin-A levels nor prognostic effect for the progression to microalbuminuria in this population.

These results came in agreement with the findings of Zeidan et al. ${ }^{18}$ and Maharem et al. ${ }^{36}$ who conducted their study on Egyptian chronic kidney disease patients(CKD) and found no statistically significant difference between $\mathrm{CKD}$ patients and control groups regarding the frequencies of the three fetuin-A genotypes $(C \rightarrow G)$, and no significant difference was found between fetuin-A genotypes as regards vascular calcification and atherosclerosis assessed by measurement of intimamedia thickness. However, Ma et al., ${ }^{8}$ found that frequencies of the GG genotype and the G allele in fetuin-A (rs4918) were significantly higher in patients with ischemic stroke or atherosclerotic cerebral infarction than those in the control group.

The lack of association with serum fetuin-A levels in this study may be explained by reduced sample size that does not provide adequate statistical power to detect genetic associations of modest effect. Also, it may be attributed to the different populations. Moreover, it seems possible that the use of diabetes medications by our study participants could influence fetuin-A levels, which need further investigations.

Although the underlying mechanisms of endothelial dysfunction and kidney damage in type $2 \mathrm{DM}$ are multifactorial, substantially evidence suggests that increased reactive oxygen species (ROS) may be a cause.$^{37}$ In the present study, significant higher levels of both NO and IMA in microalbuminuric diabetic patients as compared to normoalbuminuric diabetic patients and controls were detected, which came in accordance with several studies, ${ }^{38-40}$ but in contrast to others. $^{41,42}$ 
Prolonged exposure of endothelial cells to high glucose increases both NO and superoxide anion production. It enhances NO synthesis by endothelial cell NO synthase (eNOS) in afferent arterioles and glomerular endothelial cells leading to preferential dilatation of afferent arterioles, which ultimately induces glomerular enlargement and glomerular hyper filtration, which in turn leads to an increase in urinary albumin excretion and thus causes progression of nephropathy in early type 2 diabetes. ${ }^{43}$

Also, the observed high levels of IMA here-in may be due to local overproduction of ROS in the diabetic kidney or the altered catabolism of modified albumin in the kidney which supports the involvement of oxidative stress and ischemic-hypoxia in pathogenesis of diabetic complications. ${ }^{40}$

Ukinc et al. ${ }^{44}$ in their study, stated that elevated IMA in diabetic patients is due to uncontrolled oxidative stress occurs on endothelium due to hyperglycemia and presence of other conventional risk factors and the effects of subsequently released reactive oxygen types on albumin. Since IMA levels were high in patients with MA and it was positively associated with hsCRP and MA levels, they think that they may accept IMA as a novel risk factor and a marker in diabetic patients for extensive endothelial dysfunction, low grade inflammation, and macrovascular disease that may develop in the future. In the view of all of these outcomes, IMA can be an additional parameter to show sub-clinic vascular disease.

\section{Limitations}

There is several weakness of the study:

i. Previous studies have demonstrated elevated IMA in coronary heart disease and end-stage renal disease, so the event is not necessarily predictive of diabetes per se but rather the degree of cardiovascular disease accompanying diabetes.

ii. One of the limitations of this study is the small sample size of the patients with MA. This, of course, would need further verification in larger patient populations. However, we believe that this did not affect our results and reliability of the study.

\section{Conclusion}

High level of fetuin-A, which is the most important predictors of MA, may lead to endothelial dysfunction in systemic and renal blood vessels and predispose these patients to increased risks of both MA and cardiovascular disease, through its effect on either lipid profile, IR or endothelial dysfunction but, with lack of the effect of its risky rare genotypes (CG, GG). So fetuin-A could be a potential novel target for not only the treatment and/or prevention of human IR in type 2 diabetes mellitus patients, but also of its vascular complications including MA. Our study supported the involvement of oxidative stress in pathogenesis of diabetic nephropathy and IMA may be a helpful clinical marker in estimating kidney dysfunction in diabetic patients. Also, the microalbuminuric DN stage would be more suitable for antioxidative intervention.

\section{Acknowledgements}

None.

\section{Conflict of interest}

Author declares that there is no conflict of interest.

\section{References}

1. Hasan MJ, Muqueet A, Sharmeen A, et al. Prevalence of microalbuminuria in relation to glycemic control in type-2 diabetic patients in Mymensingh. Mymensingh Med J. 2015;24(1):18-24.

2. Yokoyama H, Sone H, Oishi M, et al. Prevalence of albuminuria and renal insufficiency and associated clinical factors in type 2 diabetes: the Japan Diabetes Clinical Data Management study (JDDM15). Nephrol Dial Transplant. 2009;24(4):1212-1219.

3. Muniyappa R, Sowers JR. Role of insulin resistance in endothelial dysfunction. Reviews in endocrine \& metabolic disorders. 2013;14(1):5-12.

4. Prabhakar SS. Pathogenic role of nitric oxide alterations in diabetic nephropathy. Current diabetes reports. 2005;5(6):449-454.

5. Zuwala-Jagiello J, Warwas M, Pazgan-Simon M. Ischemia-modified albumin (IMA) is increased in patients with chronic hepatitis $\mathrm{C}$ infection and related to markers of oxidative stress and inflammation. Acta biochimica Polonica. 2012;59(4):661-667.

6. Yin L, Cai WJ, Zhu LY, et al. Association of plasma Fetuin-A and clinical characteristics in patients with new-onset type 2 diabetes mellitus. Int $J$ Clin Exp Med. 2015;8(1):991-999.

7. Shidfar F, Zarrati M, Khamseh ME, et al. Relationship between serum levels of fetuin-A with apo-A1, apo-B100, body composition and insulin resistance in patients with type 2 diabetes. Med J Islam Repub Iran. 2014;28:100.

8. Ma S, He Z, Zhao J, et al. Association of AHSG gene polymorphisms with ischemic stroke in a Han Chinese population. Biochemical genetics. 2013;51(11-12):916-926.

9. Gansevoort RT, Verhave JC, Hillege HL, et al. The validity of screening based on spot morning urine samples to detect subjects with microalbuminuria in the general population. Kidney Int Suppl. 2005;(94):S28-35.

10. Cambiaso CL, Collet-Cassart D, Lievens M. Immunoassay of low concentrations of albumin in urine by latex particle counting. Clin Chem $1988 ; 34(2): 416-418$.

11. Murray RL, Kaplan A. Creatinine. Clin Chem. 1984;1:1261-1266.

12. Friedewald W, Levy R, Fredrickson D. Estimation of the concentration of low-density lipoprotein cholesterol in plasma, without use of the preparative ultracentrifuge. Clin Chem. 1972;18:499-502.

13. Levey AS, Coresh J, Greene T, et al. Using standardized serum creatinine values in the modification of diet in renal disease study equation for estimating glomerular filtration rate. Annals of internal medicine. 2006;145(4):247-254.

14. Montgomery HAC, Dymock JF. Colorimetric Determination of nitrite. Analyst. 1961;86:414.

15. Bar-Or D, Lau E, Winkler JV. A novel assay for cobalt-albumin binding and its potential as a marker for myocardial ischemia-a preliminary report. The Journal of emergency medicine. 2000;19(4):311-315.

16. Matthews DR, Hosker JP, Rudenski AS, et al. Homeostasis model assessment: insulin resistance and beta-cell function from fasting plasma glucose and insulin concentrations in man. Diabetologia. $1985 ; 28(7): 412-419$

17. Aksoy H,Aksoy Y, Ozturk N, et al. Fetuin-Agene polymorphism in patients with calcium oxalate stone disease. Urology. 2010;75(4):928-932.

18. Zeidan MA, Sharara GM, Suliman HS, et al. Visfatin and Fetuin-A Novel Markers for Endothelial Dysfunction in Chronic Kidney Disease. Life Science Journal. 2012;9(2):227-43. 
19. Huddam B, Azak A, Kocak G, et al. The relationship between serum fetuin-A, cystatin-C levels, and microalbuminuria in patients with metabolic syndrome. Journal of clinical laboratory analysis. 2013;27(4):317-322.

20. Inoue K, Wada J, Eguchi J, et al. Urinary fetuin-A is a novel marker for diabetic nephropathy in type 2 diabetes identified by lectin microarray. PloS one. 2013;8(10):e77118.

21. Ramadan A, Shoukry A, Ismail M, et al. Serum fetuin-A Levels in Type 2 Diabetes Patients with Early Diabetic Nephropathy: It's Relation to Diabetes Control. Journal of American Science. 2011;7(5):759-765.

22. Jung CH, Kim BY, Kim CH, et al. Associations of serum fetuin-A levels with insulin resistance and vascular complications in patients with type 2 diabetes. Diab Vasc Dis Res. 2013;10(5):459-467.

23. Stefan N, Fritsche A, Weikert C, et al. Plasma fetuin-A levels and the risk of type 2 diabetes. Diabetes. 2008;57(10):2762-2767.

24. Ishibashi A, Ikeda Y, Ohguro T, et al. Serum fetuin-A is an independent marker of insulin resistance in Japanese men. Journal of atherosclerosis and thrombosis. 2010;17(9):925-933.

25. Ix JH, Biggs ML, Mukamal KJ, et al. Association of fetuin-a with incident diabetes mellitus in community-living older adults: the cardiovascular health study. Circulation. 2012;125(19):2316-2322.

26. Esteghamati A, Ashraf H, Nakhjavani M, et al. Insulin resistance is an independent correlate of increased urine albumin excretion: a crosssectional study in Iranian Type 2 diabetic patients. Diabetic medicine. 2009;26(2):177-181.

27. Hsu CC, Chang HY, Huang MC, et al. Association between insulin resistance and development of microalbuminuria in type 2 diabetes: a prospective cohort study. Diabetes care. 2011;34(4):982-987.

28. Parvanova AI, Trevisan R, Iliev IP, et al. Insulin resistance and microalbuminuria: a cross-sectional, case-control study of 158 patients with type 2 diabetes and different degrees of urinary albumin excretion. Diabetes. 2006;55(5):1456-1462.

29. Ix JH, Sharma K. Mechanisms linking obesity, chronic kidney disease, and fatty liver disease: the roles of fetuin-A, adiponectin, and AMPK. $J$ Am Soc Nephrol. 2010;21(3):406-412.

30. Dogru T, Genc H, Tapan S, et al. Plasma fetuin-A is associated with endothelial dysfunction and subclinical atherosclerosis in subjects with nonalcoholic fatty liver disease. Clinical endocrinology. 2013;78(5):712-717

31. Khalil H, Faizehalkuobaili. Elevated Fetuin - A Level Associated with an Atherogenic Lipid Profile in Type 2 Diabetes. International Journal of Pharmaceutical Sciences Review and Research. 2013;21:266-269.

32. Ling Y, Li X, Gu Q, et al. Circulating ApoE level is independently associated with urinary albumin excretion in type 2 diabetic patients. Internal medicine. 2011;50(24):2961-2966.
33. Osawa M, Yuasa I, Kitano T, et al. Haplotype analysis of the human alpha2-HS glycoprotein (fetuin) gene. Annals of human genetics. 2001;65(Pt 1):27-34

34. Osawa M, Tian W, Horiuchi $\mathrm{H}$, et al. Association of alpha2-HS glycoprotein (AHSG, fetuin-A) polymorphism with AHSG and phosphate serum levels. Human genetics. 2005;116(3):146-151.

35. Siddiq A, Lepretre F, Hercberg S, et al. A synonymous coding polymorphism in the alpha2-Heremans-schmid glycoprotein gene is associated with type 2 diabetes in French Caucasians. Diabetes. 2005;54(8):2477-2481.

36. Maharem DA, Gomaa SH, El Ghandor MK, et al. Association of serum fetuin-A and fetuin-A gene polymorphism in relation to mineral and bone disorders in patients with chronic kidney disease. The Egyptian Journal of Medical Human Genetics. 2013;14:337-352.

37. Münzel T, Sinning C, Post F, et al. Pathophysiology, diagnosis and prognostic implications of endothelial dysfunction. Ann Med. 2008;40(3):180-196.

38. Apakkan Aksun S, Ozmen B, Ozmen D, et al. Serum and urinary nitric oxide in Type 2 diabetes with or without microalbuminuria: relation to glomerular hyperfiltration. Journal of diabetes and its complications. 2003;17(6):343-348.

39. Dahiya K, Kumawat M, Kaur R, et al. Ischemia modified albumin and nitric oxide in diabetic nephropathy. Journal of Diabetology. 2013;1(1):1-5.

40. Piwowar A, Knapik-Kordecka M, Warwas M. Comparison of the usefulness of plasma levels of oxidatively modified forms of albumin in estimating kidney dysfunction in diabetic patients. Clinical and investigative medicine Medecine. 2010;33(2):E109.

41. Shahid S, Shaikh R, Nawab S, et al. Serum Nitric Oxide and Sialic Acid: Possible Biochemical Markers for Progression of Diabetic Nephropathy. World Academy of Science, Engineering and Technology. 2010;46:73-76.

42. Tousoulis D, Papageorgiou N, Androulakis E, et al. Diabetes mellitusassociated vascular impairment: novel circulating biomarkers and therapeutic approaches. Journal of the American College of Cardiology. 2013;62(8):667-676.

43. Hoshiyama M, Li B, Yao J, et al. Effect of high glucose on nitric oxide production and endothelial nitric oxide synthase protein expression in human glomerular endothelial cells. Nephron Experimental nephrology. 2003;95(2):e62-68.

44. Ukinc K, Eminagaoglu S, Ersoz HO, et al. A novel indicator of widespread endothelial damage and ischemia in diabetic patients: ischemia-modified albumin. Endocrine. 2009;36(3):425-432. 